\title{
ELEIÇÕES GERAIS DE 2014: RELIGIÃO E POLÍTICA NO RIO GRANDE DO SUL
}

\author{
Ari Pedro Oro ${ }^{1}$ \\ Erico Tavares de Carvalho Junior ${ }^{2}$
}

Resumo: Este texto efetua um balanço das relações entre religião e política nas eleições de 2014 no Rio Grande do Sul. Mais especificamente, analisa as aproximações dos candidatos ao executivo estadual com segmentos religiosos, notadamente os evangélicos, bem como as candidaturas de indivíduos que acionaram seus vínculos religiosos na disputa de vagas para a câmara federal e o legislativo estadual. Por fim, será realizada uma breve análise comparativa entre os pleitos de 2010 e 2014 no que se refere às imbricações entre religião e política.

Palavras-chave: Religião; Política; Rio Grande do Sul; Eleições 2014.

Abstract: This paper evaluates the relationship between religion and politics in the 2014 elections in Rio Grande do Sul. More specifically, it analyzes the approaches of candidates for the state executive toward religious segments, particularly evangelicals. It also analyzes the candidacy from individuals who triggered their religious ties in the dispute for vacancies in the chamber of deputies and the state legislature. Finally, it holds a brief comparative analysis of the 2010 and 2014 elections, regarding to the overlapping of religion and politics.

Keywords: Religion; Politics; Rio Grande do Sul; 2014 Elections.

1 Professor do Departamento de Antropologia e do Programa de Pós-Graduação em Antropologia da Universidade Federal do Rio Grande do Sul. Contato: arioro@uol.com.br

2 Estudante de Graduação do Curso de Ciências Sociais da UFRGS e bolsista BIC/UFRGS do Núcleo de Estudos da Religião (NER). Contato: erico.carvalho@hotmail.com

Debates do NER, Porto Alegre, Ano I6, N. 27, P. I45-I7I, JAn./Jun. 2015 


\section{INTRODUÇÃO}

No Brasil, mas não somente aqui, religião e política são esferas que se comunicam e dialogam entre si, especialmente por ocasião dos pleitos eleitorais, denotando, dessa forma, a existência de uma instrumentalização mútua entre essas duas esferas sociais (Mariano; Oro, 2011). Este texto procura analisar como esta relação ocorreu nas eleições gerais de 2014 no Rio Grande do Sul. Uma perspectiva comparativa com o que ocorreu nas eleições de 2010 relativamente à aproximação com o religioso também será realizada neste texto, para melhor compreender as especificidades e as recorrências dos processos eleitorais.

Será aqui privilegiada uma abordagem empírico-ilustrativa dos fatos, a qual não contempla a análise de tópicos sensíveis como as motivações das aproximaçôes entre religiosos e políticos no "tempo da política" e as implicações de ordem teórica que isto suscita. Estes temas já foram contemplados em outros textos (Oro, 2003; 2007; 2010) e por outros tantos autores, entre eles Hervieu-Léger (1997), Michel (1997), Burity (2000), Novaes (2001), Ribeiro (2002), Burity e Machado (2006), Moreira e Mariano (2012).

\section{A RELIGIÃO E OS RELIGIOSOS NAS ELEIÇÕES 2014 NO RIO GRANDE DO SUL}

Iniciamos a análise das articulações entre religião e política ocorridas relativamente às disputas ao governo do estado do Rio Grande do Sul e ao seu representante ao senado federal. Posteriormente, a mesma análise será feita no tocante às vagas à Câmara Federal e à Assembleia Legislativa.

\section{GOVERNO ESTADUAL}

Nas eleiçôes de 2014, sete candidatos concorreram ao governo do estado do Rio Grande do Sul. São eles: José Ivo Sartori (PMDB), Tarso Genro (PT), Vieira da Cunha (PDT), Ana Amelia Lemos (PP), Edison Estivalete (PRTB), Humberto Carvalho (PCB) e Roberto Robaina (PSOL). A análise 
a seguir centrar-se-á apenas nos quatro primeiros, devido à sua votação e às suas aproximações com os segmentos religiosos do estado. Salienta-se, porém, que, ao contrário de José Ivo Sartori, nenhum dos outros candidatos explicitou seu pertencimento religioso.

José Ivo Sartori é um católico assumido, ex-seminarista. Formado em filosofia, elegeu-se vereador de Caxias do Sul, em 1976, e deputado estadual por cinco vezes (1982, 1986, 1990, 1994 e 1998). Em 2002, foi eleito deputado federal, renunciando em 2004 para concorrer à prefeitura de Caxias do Sul, cargo ao qual se elegeu, sendo reeleito em 2008. Durante a última campanha, trabalhou uma imagem de simplicidade, associada à sua origem proveniente de uma família de agricultores, descendentes de imigrantes italianos e católicos. Não buscou apoio explícito nos setores religiosos, a não ser a produção da sua própria imagem de católico, associada à ideia de cidadão rio-grandense, da qual aparentemente derivou seu sucesso. Aqui é interessante notar que, ao menos no caso do Rio Grande do Sul, o investimento do candidato nessa imagem estereotipada associada a uma religiosidade hegemônica, torna desnecessário uma maior aproximação aos segmentos católicos. Também vale ressaltar que parte do seu sucesso eleitoral se deve a uma já clássica disputa no RS entre o PT e o PMDB (que ocupa o governo do Estado pela quarta vez). O candidato chegou ao segundo turno com Tarso Genro, vencendo o pleito com 3.859.611 votos $(61,21 \%)$.

Tarso Genro é formado em direito e possui uma longa carreira política. Foi vereador em Santa Maria pelo MDB (1969-1972), depois, já pertencente ao PT (Partido dos Trabalhadores), foi vice-prefeito de Porto Alegre por duas vezes (1988-1989 e 1990-1992), deputado federal pelo Rio Grande do Sul (1989-1990), prefeito de Porto Alegre por dois mandatos (1993-1996 e 2001-2002), ocupou secretarias e ministérios do governo federal entre 2003 e 2010, e foi eleito governador do Estado em 2010. Durante a campanha, deu ênfase ao discurso da diversidade e do pluralismo religioso, sem grande ênfase nas alianças pré-existentes. Recebeu o apoio do PR, sigla que conta com grande apoio pentecostal, como da Assembleia de Deus, da Igreja Batista, da Igreja Presbiteriana e mais recentemente da Igreja Mundial do Poder de Deus.

Debates do NER, Porto Alegre, Ano i6, N. 27, P. I45-I7I, JAn./Jun. 2015 
Em uma análise retrospectiva mais abrangente, percebemos um diálogo constante do candidato com os setores religiosos nos meses que antecederam o pleito eleitoral. Assim, em doze de dezembro de 2013, encontrou-se, em reunião-almoço, com cerca de setecentos pastores evangélicos, entre eles o presidente do Conselho de Pastores de Porto alegre, Isaías Figueiró (Encontros de Fé), o Pr. Roberto Machado (Brasil para Cristo), o Pr. Egon Koberec (Igreja Evangélica Luterana do Brasil) e o Pr. Ubiratan Batista Job (Assembleia de Deus) ${ }^{3}$. Em 26 de março de 2014, falou na Convenção das Igrejas Evangélicas e Pastores da Assembleia de Deus do Rio Grande do Sul, em Itaara, declarando: "Não permitimos que o Estado seja laicizado ao contrário, ou seja, que se relacione apenas com um grupo religioso, mas dialogamos com todas as organizações com olhar para o ser humano" ${ }^{\prime \prime}$. Em 9 de maio realizou uma reunião-almoço com várias lideranças evangélicas do estado, entre elas o Pr. Christian Lo Iacono (Encontros de Fé), o Pr. Hudson Teilor Rodrigues (Igreja Batista Brasa) e o Pr. Ubiratan Batista Job (Assembleia de Deus) $)^{5}$. Relativamente ao segmento afro-religioso, o candidato manteve a política petista de valorização da cultura afro e luta contra a discriminação, comparecendo, no dia 28 de março, na I Conferência Estadual do Povo de Terreiro. Na ocasião, declarou: "Essas religiōes sempre foram segregadas, sempre foram identificadas como religião dos oprimidos, dos explorados, dos excluídos dentro da história do nosso Brasil" ${ }^{6}$. Vale recordar que em seu mandato foi articulado e constituído o Comitê Estadual de Povo de Terreiro, inaugurado no Palácio Piratini. Durante a campanha, o candidato também compareceu no Encontro de Povos de Terreiros, no

3 Disponível em: <http://www.convensul.com.br/noticia/tarso-genro-se-reune-com700-lideres-evangélicos-do-rs/\#.VDaVxfldWSo>. Acesso em: 9 out. 2014.

4 Disponível em: <http://www.rs.gov.br/conteudo/193920/governador-participa-deencontro-evangélico-na-região-central>. Acesso em: 16 out. 2014.

5 Disponível em: <http://www.saladeimprensamormon.org.br/artigo/lideres-religiososalmocam-com-governador-tarso-genro>. Acesso em: 9 out. 2014.

6 Disponível em: <http://www.rs.gov.br/conteudo/194090/governador-participa-dai-conferencia-estadual-do-povo-de-terreiro>. Acesso em: 16 out. 2014.

Debates do NER, Porto Alegre, Ano i6, N. 27, P. I45-I7I, JAN./Jun. 2015 
Largo Zumbi dos Palmares, em Porto Alegre, em trinta de setembro. ${ }^{7}$ No segundo turno, obteve 2.445 .664 votos $(38,79 \%)$, perdendo as eleiçōes para José Ivo Sartori.

Ana Amelia Lemos, jornalista, natural de Lagoa Vermelha/RS, elegeu-se senadora em 2010, com 3.401.241 votos, considerada uma candidata conservadora, representante dos interesses rurais, recebendo o apoio da grande mídia (representada na figura do Grupo RBS). Formou a coligação Esperança que une o Rio Grande, com seu partido PP (Partido Progressista), além do PSDB (Partido Social Democrata Brasileiro), SD (Solidariedade) e PRB (Partido Republicano Brasileiro), partido considerado braço político da Igreja Universal do Reino de Deus (IURD), recebendo, aliás, o apoio explícito desta denominação. Timidamente buscou o apoio de outros segmentos evangélicos antes mesmo do período eleitoral, como no dia 26 de abril, quando participou do $16^{\circ}$ Encontro da Mulher Obreira da Igreja Evangélica Assembleia de Deus, em Canoas ${ }^{8}$. Ficou em terceiro lugar, com 1.342 .115 votos $(21,79 \%)$.

O candidato Vieira da Cunha foi eleito vereador de Porto Alegre duas vezes (1986 e 1989), deputado estadual por três mandatos e deputado federal em 2006 e 2010. Foi apoiado pelo PSC (Partido Social Cristão), partido que tem como ampla base os segmentos evangélicos mais conservadores, oriundos de pequenas denominações. Ficou em quarto lugar, com 263.062 $\operatorname{votos}(4,27 \%)$.

\section{SenAdo}

Para o senado, tivemos apenas um candidato declaradamente religioso, o vereador e pastor da Igreja Universal, Waldir Canal (PRB), que entrou como segundo suplente da candidata Simone Leite (PP), os quais receberam

7 Disponível em: <http://www.sul21.com.br/jornal/tarso-genro-participa-do-encontrodos-povos-de-terreiros/>. Acesso em: 20 out. 2014.

8 Disponível em: <https://www.facebook.com/anaamelialm>. Acesso em: 16 out. 2014.

Debates do NER, Porto Alegre, Ano I6, N. 27, P. I45-I7I, JAn./Jun. 2015 
uma votação baixa, 606.329 votos (10,58\%), figurando em quarto lugar? Melhor resultado obteve o candidato Lasier Martins (PDT), que recebeu o apoio do Partido Social Cristão (PSC), elegendo-se com 2.145.479 votos (37,42\%), apenas 121.062 votos à frente do candidato Olivio Dutra (PT). O sucesso eleitoral do candidato vencedor deu-se principalmente devido à sua atuação como jornalista durante 26 anos, tendo sido alvo preferencial do voto conservador.

\section{Candidatos religiosos à CÂMara Federal}

No Rio Grande do Sul, nas eleições de 2014, compareceram 308 candidatos a deputado federal, que disputavam 31 vagas. Daquele total, dezoito acionaram sua identidade religiosa durante a campanha eleitoral. Foram quatorze evangélicos e quatro católicos ${ }^{10}$. Dentre os evangélicos, dois candidatos foram por nós assim considerados, posto que sua filiação religiosa é publicamente conhecida, apesar de não ser acionada por ocasião do pleito.

9 Como já havíamos apontado em outro texto (Oro; Junior, 2013), além de pastor, Waldir Canal é comunicador de rádio e de TV (Record). É carioca e em 1993 mudou-se para o Rio Grande do Sul. Foi vereador em Sapucaia do Sul por dois mandatos (2000-2004 e 2005-2008). Em 2008, foi eleito vereador em Porto Alegre com 7.046 votos, sendo o primeiro vereador do PRB a ser eleito na capital, e reeleito pelo mesmo partido em 2012, com 8.211 votos.

${ }^{10}$ A título de informação, vale destacar que tomando como base apenas as listagens das candidaturas disponibilizadas pelo Tribunal Regional Eleitoral (TRE) constatamos que, em todo o país, 431 candidatos explicitaram sua identidade religiosa através de um título religioso associado ao nome, mais especificamente, entre os cristãos, foram 224 pastores (a), 85 irmãos (a), 50 missionários (a), 21 bispos (a), 11 apóstolos (a), 15 padres, e 2 freis. Entre os afro-religiosos, foram 1 pai, 4 mães e outros 3 que utilizaram nomes associados à religião. Entre os Estados, São Paulo (53), Rio de Janeiro (39) e Minas Gerais (28) apresentaram maior número de candidatos religiosos, enquanto que Mato Grosso (3), Sergipe (5) e Piauí (6) apresentaram o menor número. Obviamente que os dados acima são limitados pelo desconhecimento dos contextos locais de cada Estado, o que dificulta a identificação de outros candidatos que acionaram de outras formas uma identidade religiosa.

Debates do NER, Porto Alegre, Ano I6, N. 27, P. I45-I7I, JAN./Jun. 2015 


\section{Evangélicos}

Os quatorze candidatos evangélicos pertenciam às seguintes denominações: Assembleia de Deus (4), Assembleia de Deus Gideões Missionários (1), Internacional da Graça de Deus (2), Universal do Reino de Deus (1), Batista Betel (1), Quadrangular (1), Presbiteriana (1), Luterana (1), Mundial do Poder de Deus (1), 1 não declarou seu pertencimento denominacional.

Foram os seguintes os candidatos da Assembleia de Deus: Ronaldo Nogueira, de Carazinho, eleito vereador em 2004, e suplente a deputado federal em 2006 e 2010, tendo assumido a Câmara Federal em 2011. Foi indicado como candidato oficial da Assembleia de Deus e se elegeu com 77.017 votos; Oséas Costa, pastor e músico, de Santa Maria, já havia concorrido ao cargo em 2006 e a deputado estadual em 2010, chegando à suplência com 15.851 votos; Iran Jasper, pastor de Caxias do Sul, e Eder Neves Leal, presbítero de São Borja, ambos concorrendo pela primeira vez. Ainda da Assembleia de Deus Gideões Missionários, concorreu o cantor Vilmar de Souza, de Caxias do Sul.

A Igreja Internacional da Graça de Deus apresentou dois candidatos: Gauchinho de Deus, cantor gospel, natural de São Luiz Gonzaga, já conhecido no meio eleitoral por ter concorrido a um cargo eletivo nos anos 2008, 2010 e 2012, e a advogada Roseli Poggere, de Erechim, concorrendo pela primeira vez.

Pela Igreja Universal, concorreu o pastor Carlos Gomes, eleito duas vezes para a Assembleia Legislativa, em 2006 e em 2010. Foi eleito no pleito de 2014 com 92.323 votos. Da Igreja Batista Betel, concorreu, sem êxito, o pastor Getúlio Vargas, que já havia disputado, também sem sucesso, a eleição de 2010.

A Igreja Quadrangular apresentou um candidato oficial à Câmara de Deputados. Trata-se do pastor Airton Lima, de Cachoeira do Sul, que concorreu pela primeira vez, não logrando obter sua eleição.

Outros dois candidatos foram também considerados por sua conhecida filiação religiosa, apesar de não acionarem sua identidade religiosa por ocasião da campanha eleitoral. São eles: João Derly, ex-judoca, membro da Igreja Presbiteriana do Brasil e o segundo vereador mais votado em Porto

Debates do NER, Porto Alegre, Ano I6, N. 27, P. I45-I7I, JAN./Jun. 2015 
alegre em 2012, que obteve 14.038 votos, e Onyx Lorenzoni, membro da Igreja Evangélica de Confissão Luterana do Brasil, que já possui um mandato como deputado estadual (1998) e três como deputado federal (2002, 2006 e 2010), integrando oficialmente a Bancada Evangélica no Congresso Nacional ${ }^{11}$. Ambos foram eleitos.

É válido recordar que, no caso de João Derly e Onyx Lorenzoni, assim como o ocorrido com a eleição do prefeito de Porto Alegre, José Fortunati, em 2012, e sua esposa nesta eleição, há um elemento de associação indireta da religião à figura dos candidatos. Ou seja, apesar de não ser explorada diretamente como recurso eleitoral, esta informação circula no meio evangélico e condiciona em alguma medida o voto nestes candidatos que, em alguns casos, como o de João Derly, chega a fazer campanha no meio religioso, sem, no entanto, tocar na temática religiosa. Além disso, a propósito do candidato Joao Derly, é preciso informar que a sua votação se deveu também à importante influência da ex-deputada federal Manuela D’Ávila, a qual, sem dúvida, conquistou muitos votos para o ex-judoca. Esta candidata, depois de alguns mandatos na câmara federal, lançou-se como pretendente à Assembleia Legislativa Estadual, tendo sido eleita com 222.436 votos. O seu apoio foi decisivo para a eleição de João Derly. Ambos concorreram pelo PCdoB.

O candidato Cajar Nardes, presidente do PR no Rio Grande do Sul, apesar de não se declarar membro da Igreja Mundial do Poder de Deus, recebeu seu apoio, realizando campanha junto com o Missionário Volnei Alves; ambos apareceram juntos no material de campanha com o Apóstolo Valdomiro Santiago, fundador e líder máximo daquela igreja pentecostal. No dia seis de abril, foi abençoado pelo Apóstolo em sua visita ao Rio Grande do Sul, durante a Festa da Uva. ${ }^{12}$ No dia quinze de agosto, acrescentou

${ }^{11}$ Disponível em: <www.diap.org.br/index.php?option=com_content\&view=article\&id $=14637 \&$ Itemid=296>. Acesso em: 28 set. 2014.

12 Disponível em: <http://partidodarepublica.com.br/noticias/ver/cod/140>. Acesso em: 14 nov. 2014.

Debates do NER, Porto Alegre, Ano i6, N. 27, P. I45-I7I, JAN./Jun. 2015 
em seu Facebook o comentário: "O Missionário Volnei e eu Cajar Nardes fomos Ungidos pelo Apóstolo Valdomiro Santiago. Nessa eleição somos Candidatos pela Igreja Mundial, vamos juntos na Fé."

Tivemos ainda um candidato, Julian Narciso, de Guaíba, que apesar de se declarar abertamente evangélico, não revelou a qual denominação pertence.

A tabela a seguir apresenta uma síntese informativa dos candidatos evangélicos do Rio Grande do Sul à Câmara Federal. Nota-se que quatro deles foram eleitos, e que, juntos, os quatorze candidatos evangélicos somaram um total de 589.417 votos.

Tabela 1 - Evangélicos candidatos a deputado federal

\begin{tabular}{c|c|c|c|c|c}
\hline Nome & Partido & Filiação Religiosa & Relação & Votos & Eleitos \\
\hline Carlos Gomes & PRB & IURD & Pastor & 92.323 & Eleito \\
\hline Ronaldo Nogueira & PTB & AD & Pastor & 77.017 & Eleito \\
\hline João Derly & PCdoB & Igreja Presbiteriana & Membro & 106.991 & Eleito \\
\hline Onyx Lorenzoni & DEM & Luterana do Brasil & Membro & 148.302 & Eleito \\
\hline Cajar Nardes & PR & IMPD & - & 55.434 & Não Eleito \\
\hline Eder Neves Leal & PSC & AD & Presbítero & 1.074 & Não Eleito \\
\hline Oséas Costa & PP & AD & Pastor & 18.613 & Não Eleito \\
\hline Iran Jasper & PSC & AD & Pastor & 296 & Não Eleito \\
\hline Getúlio Vargas & PSL & Batista Betel & Pastor & 2.237 & Não Eleito \\
\hline Vilmar de Souza & PSC & Gideões Missionários & Cantor & 390 & Não Eleito \\
\hline Airton Lima & PTB & Quadrangular & Pastor & 31.924 & Não Eleito \\
\hline Roseli Poggere & PSB & IIGD & Membro & 31.606 & Não Eleita \\
\hline Gauchinho de Deus & PSC & IIGD & Cantor & 20.909 & Não Eleito \\
\hline Julian Narciso & PDT & Não Identificada & Membro & 2.301 & Não Eleito \\
\hline Total & & & & $\mathbf{5 8 9 . 4 1 7}$ & \\
\hline Fone: & & &
\end{tabular}

Fonte: Organizado pelos autores.

Debates do NER, Porto Alegre, Ano i6, N. 27, P. I45-I7I, JAn./Jun. 2015 


\section{Católicos}

Nas eleições 2014, quatro candidatos à Câmara Federal pelo Rio Grande do Sul declararam-se católicos. São eles: Wambert Di Lorenzo, advogado, professor da PUCRS, concorreu na última eleição à prefeitura de Porto Alegre, obtendo uma votação baixa (2,46\%). Possui fortes laços com a Igreja Católica, sendo membro da Ordem de Malta ${ }^{13}$; Marlene Backes, pedagoga e catequista, eleita vereadora em Presidente Lucena por três vezes consecutivas; Julio César, advogado, eleito vereador em Rio Grande, em 2012; e Hermes Spolaor, membro Centro de Tradições Gaúchas Alma Crioula, faz parte do Conselho da Igreja São João Batista de Canoas. Nenhum deles conseguiu eleger-se nessa eleição.

A tabela a seguir apresenta uma síntese informativa dos candidatos católicos do Rio Grande do Sul à Câmara Federal. Nenhum deles foi eleito.

Tabela 2 - Católicos candidatos a deputado federal

\begin{tabular}{c|c|c|c|c|c}
\hline Wambert Di Lorenzo & PSD & Católico & Membro & 13.074 & Não Eleito \\
\hline Julio César & PMDB & Católico & Membro & 16.421 & Não Eleito \\
\hline Marlene Backes & PMDB & Católica & Membro & 1.317 & Não Eleita \\
\hline Hermes Spolaor & PMDB & Católico & Membro & 1.999 & Não Eleito \\
\hline Total & & & & $\mathbf{3 2 . 8 1 1}$ & \\
\hline
\end{tabular}

Fonte: Organizado pelos autores.

${ }^{13}$ Como já dissemos em outro lugar (Oro; Junior, 2013), este candidato é também membro da Cruz Vermelha e do Instituto Jacques Maritain, foi consagrado Cavaleiro de Graça Magistral em 2010 e Cavaleiro da Ordem do Santo Sepulcro (Vaticano), em 2005. Também possui fortes ligações com o Exército, principalmente com a Associação dos Ex-combatentes da FEB.

Debates do NER, Porto Alegre, Ano I6, N. 27, P. I45-I7I, JAN./Jun. 2015 


\section{Candidatos Religiosos a Deputado estadual}

No estado do Rio Grande do Sul, concorreram 675 candidatos a 55 vagas para Deputado Estadual, dos quais ao menos 36 acionaram a sua identidade religiosa durante a campanha eleitoral. Foram 31 evangélicos, assim divididos: 4 da Assembleia de Deus, 1 da Igreja Universal, 1 da Igreja Mundial do Poder de Deus, 1 da Igreja Internacional da Graça de Deus, 1 da Igreja Quadrangular, 1 da Metodista Wesleyana, 2 da Igreja Batista Filadélfia, 7 de denominações pentecostais independentes e 13 que não explicitaram seu pertencimento denominacional. Tivemos ainda 2 afro-religiosos, sendo 1 deles pai-de-santo, 1 espírita ou espiritualista, e 3 católicos, 1 dos quais é sacerdote.

\section{Candidatos evangélicos}

Nas eleições de 2014, três candidatos evangélicos lograram ser eleitos para a Assembleia Legislativa do estado do Rio Grande do Sul. Sérgio Peres, pastor da IURD, natural de Santo Antônio da Patrulha, que já havia sido eleito para a Assembleia Legislativa em 2002 pelo PSB (46.652). Deixou a vida política para se dedicar à atividade religiosa na região de Bagé. Retornou nesta eleição, elegendo-se em sexto lugar, com 67.002 votos, 548 votos a mais do que o pastor Carlos Gomes, então candidato da denominação à Assembleia Legislativa em 2010; o pastor e missionário, Volnei Alves, um dos líderes da Igreja Mundial do Poder de Deus na região metropolitana, ao lado do Bispo Darker Douglas, que declarou que sua candidatura faz parte de um projeto da igreja, sendo ele escolhido como candidato em um encontro que contou com mais de trezentos pastores ${ }^{14}$. Foi eleito com 33.255 votos, quadruplicando a votação obtida pelo candidato da

\footnotetext{
${ }^{14}$ Em entrevista ao programa Assembleia Entrevista. Disponível em: <http://www2.al.rs. gov.br/noticias/ExibeNoticia/tabid/5374/Default.aspx?IdMateria=295052>. Acesso em: 14 nov. 2014.
}

Debates do NER, Porto Alegre, Ano i6, N. 27, P. I45-I7I, JAn./Jun. 2015 
denominação em 2010, que obteve 8.040 votos; a pastora Liziane Bayer, filha do missionário Alcides Bayer, líder da Igreja Internacional da Graça de Deus no Rio Grande do Sul, a qual foi escolhida como candidata oficial da igreja. Foi eleita com 29.121 votos.

A Assembleia de Deus contou com ao menos quatro candidatos à Assembleia Legislativa, um pastor e três membros. Nenhum deles foi eleito. Entre eles, Jurandir Maciel, o candidato oficial da denominação, natural de Canoas, é pastor da Assembleia e concorreu à prefeitura desta cidade em 2008, ficando na suplência a deputado estadual em 2010, com 29.564 votos (assumindo em 2011). Nas eleições de 2014, ficou novamente na suplência, tendo obtido 33.713 votos; Fernando Vilande, policial civil, natural do Rio de Janeiro e filho do pastor Adelino Vilande, da Assembleia de Deus de Butiá, foi eleito vereador de Palmeira das Missões em 2008 e 2012; Laura Loureiro, presidente do PSC de São Borja, concorreu pela primeira vez; Darci Domingues, advogado, natural de Barracão, vive hoje em São Leopoldo e também concorreu pela primeira vez. Ainda tivemos um candidato da Assembleia de Deus Gideões Missionários, Fabio Negrine, natural de Rio Grande, que concorreu pela primeira vez e se apresentou como ex-homossexual e ex-travesti.

Outros evangélicos concorreram, sem sucesso, a uma cadeira no legislativo estadual. São eles: o cantor Cláudio Conceição, da Igreja Batista Filadélfia de Porto Alegre, que candidatou-se nas últimas quatro eleições: em 2006, pelo PSDB e, a partir de 2008, pelo DEM; o candidato da Igreja do Evangelho Quadrangular, pastor Celso Moraes, de Itaqui, que já concorrera a deputado estadual em 2010 e foi eleito vice-prefeito em 2012; Rozélio Camargo, da Igreja Metodista Wesleyana de Uruguaiana, que concorreu pela primeira vez. Além deles, houve seis candidatos de denominações independentes. São eles: o pastor Jaderson Maretoli, da Missão Santa Maria, natural de Itaqui, que concorreu pela primeira vez; o pastor Perci Pereira, da Igreja A Glória de Deus, de São Leopoldo, o qual foi eleito vereador desta cidade em 2012; Michele Bettega, diaconisa da Igreja de Cristo de Vacaria;

Debates do NER, Porto Alegre, ANo I6, N. 27, P. I45-I7I, JAN./Jun. 2015 
o pastor Airton Borges, da Igreja Cristo é a Solução, de São Miguel das Missões; o pastor Ezequiel Welter, da Igreja Cristo é a Solução Renovada de Quaraí, já tendo concorrido a vereador, em 2012; e o pastor Marcos Calegari, da Igreja Comunidade Cristã de Sapucaia do Sul, que concorreu nas últimas três eleições.

Outros treze candidatos, apesar de se identificarem como evangélicos, principalmente em suas páginas de Facebook utilizadas para a campanha, não declararam publicamente seu pertencimento denominacional. São eles: a professora de Caxias do Sul, Eliane Campos; a psicóloga de Santa Maria, Ana Neri Knupp, que já havia concorrido a vereadora em 2012; o presidente do PSC de Porto Alegre, André Maia; o cantor gospel Jair Martins, de Novo Hamburgo; o presidente do PSC de Canoas, Vagner Santos; Mario Gonçalves, de Alvorada, que já havia concorrido a prefeito em 2012; Gilberto Santos, de Campo Bom, que também concorreu a vereador em 2012; Tarcísio de Góis, de Portão; Divaldino Luiz Pires, de Aratiba; o pastor Clovis da Silva, de Santa Rosa; o músico Paulo Roberto da Silva, de Santo Augusto, líder da banda Opus Dei; o locutor de rádio e cantor Adair Santos; e Elmar Cainelli, de Bento Gonçalves, que já havia concorrido a prefeito em 2012.

Ainda tivemos a candidatura de Regina Becker Fortunati, esposa do prefeito de Porto Alegre, José Fortunati, que é publicamente conhecida como membro da Igreja Batista Filadélfia, assim como seu esposo, mantendo ativamente contato com o segmento evangélico. Por ocasião do pleito, porém, não acionou a sua identidade religiosa; baseou a sua campanha na sua ação como defensora dos animais. Mas, como já comentamos anteriormente, o não acionamento desta identidade não significa um desconhecimento deste pertencimento por parte dos eleitores e, ainda, deve-se levar em conta a sua associação à figura de seu esposo. Foi eleita deputada com 46.788 votos.

Em um recorte por partido, vemos o PRB (Partido Republicano Brasileiro), PR (Partido da República), PSB (Partido Socialista Brasileiro), PSL (Partido Social Liberal), DEM (Democratas, anteriormente PFL), PTC

Debates do NER, Porto Alegre, Ano I6, N. 27, P. I45-I7I, JAN./Jun. 2015 
(Partido Trabalhista Cristão) e PDT (Partido Democrático Trabalhista) com um candidato evangélico em cada um deles, o PMDB (Partido do Movimento Democrático Brasileiro) com dois, o PTB (Partido Trabalhista Brasileiro) com três e o PSC (Partido Social Cristão) com dezenove. Este último, que surgiu em 1985, recebeu o seu registro oficial em 1990 e vem crescendo a cada eleição, conquistando vagas nos legislativos e prefeituras por todo país, ${ }^{15} \mathrm{sem}$, no entanto, conseguir eleger um governador ou mesmo obter uma boa votação para seus candidatos à presidência. ${ }^{16}$ Este inchamento das candidaturas do PSC pode indicar uma política institucional dos evangélicos de obterem visibilidade ou uma maior disposição em participar no pleito eleitoral, compatível, dessa forma, com o pensamento recorrente no meio evangélico de uma maior participação na política nacional. Trata-se de uma projeção que, nestas eleições de 2014, culminou com o lançamento do candidato evangélico à presidência da república, Pastor Everaldo ${ }^{17}$, além

${ }^{15}$ O PSC possui hoje treze deputados federais, um senador, 34 deputados estaduais e 1.431 vereadores.

16 Nas eleições de 1994, lançou o candidato à presidência Hernani Fortuna, que obteve o último lugar, com 0,38\% dos votos; em 1998, lançou o candidato Sergio Bueno, que ficou em penúltimo lugar, com 0,18\%; em 2006, o partido tentou lançar a candidatura de Rogério Vargas, mas este desistiu na última hora; e nas eleiçōes 2014 novamente o partido atingiu uma baixa votação, ficando em $5^{\circ}$ lugar.

17 O candidato Pastor Everaldo (PSC), nascido no Rio de Janeiro, formado em Ciências Atuariais, pastor da Assembleia de Deus e vice-presidente do PSC, apresentou um programa político totalmente vinculado às suas convicçôes religiosas, representando os setores evangélicos mais conservadores e partidários do liberalismo econômico. Sua campanha foi mais estática, recebendo apoio de alguns líderes evangélicos, mas perdendo apoio ao longo do processo. Também foi apoiado pelo pastor Silas Malafaia e pelo deputado Marco Feliciano. Apesar do apelo à fé e de representar a oportunidade para os segmentos evangélicos atingirem uma posição política de relevância, o candidato não conseguiu sensibilizar o eleitorado, recebendo apenas 780.513 votos $(0.75 \%)$. Seu fracasso eleitoral aparentemente se deu devido ao posicionamento excessivamente fundamentalista, o que desagradou principalmente os segmentos neopentecostais, em razão do seu discurso sobre o "Estado mínimo", que afastou seus eleitores, pois, segundo pesquisa Datafolha,

Debates do NER, Porto Alegre, Ano I6, N. 27, P. I45-I7I, JAN./Jun. 2015 
de novamente comparecer à disputa à presidência da república, a candidata Marina Silva, fiel da Assembleia de Deus ${ }^{18}$.

A tabela a seguir apresenta uma síntese informativa dos candidatos evangélicos que, nas eleições de 2014, pleitearam uma vaga ao legislativo estadual do Rio Grande do Sul. Quatro deles foram eleitos.

em torno de $73 \%$ creem que o Estado tem o dever de interferir na economia. Além disso, esse discurso foi associado à perda da assistência básica prestada pelo governo na saúde, educação e nos programas sociais, como o bolsa família. Disponível em: <http:// www1.folha.uol.com.br/poder/2014/09/1512202-eleitorado-de-everaldo-rejeita-estadominimo-aponta-datafolha.shtml>. Acesso em: 13 nov. 2014.

${ }^{18}$ De fato, a candidata Marina Silva (PSB), embora seja fiel da Assembleia de Deus, desde a sua candidatura à presidência pelo PV, em 2010, busca desvincular sua identidade religiosa da política, sem, no entanto, afastar o eleitorado evangélico, optando por declarar-se uma candidata laica. Em 2014, foi indicada como candidata à vice-presidência de Eduardo Campos. Seus esforços em afirmar-se como candidata laica não impediram Campos de circular pelo meio religioso. Assim, em 5 de agosto participou de evento da Assembleia de Deus que contou com cerca de 2.000 pastores, juntamente com o seu adversário Pr. Everaldo. Dias depois, em 13 de agosto, o político faleceu em um trágico acidente aéreo, assumindo Marina como candidata à presidência. A candidata obteve um aumento nas intençôes de voto, chegando a $37 \%$ no final de agosto entre os eleitores evangélicos, segundo pesquisa Ibope. Mas, logo em seguida, devido à campanha desfavorável no meio cristão, foi obrigada a optar por retirar de seu programa algumas propostas sensíveis a este segmento, como o apoio à união de pessoas do mesmo sexo, decisão que melhorou sua imagem junto a este segmento, mas lhe custou o apoio do eleitorado GLBT.

Debates do NER, Porto Alegre, ANo I6, N. 27, P. I45-I7I, JAn./Jun. 2015 
Tabela 3 - Evangélicos candidatos a deputado estadual

\begin{tabular}{|c|c|c|c|c|c|}
\hline Nome & Partido & Filiação Religiosa & Posição & Votos & Situação \\
\hline Sérgio Peres & PRB & IURD & Pastor & 67.002 & Eleito \\
\hline Volnei Alves & PR & IMPD & Missionário & 33.255 & Eleito \\
\hline Liziane Bayer & PSB & IIGD & Pastora & 29.121 & Eleita \\
\hline Regina B. Fortunati & PDT & $\begin{array}{l}\text { Igreja Batista } \\
\text { Filadélfia }\end{array}$ & Membro & 46.788 & Eleita \\
\hline Cláudio Conceição & DEM & $\begin{array}{l}\text { Igreja Batista } \\
\text { Filadélfia }\end{array}$ & Cantor & 7.183 & Não Eleito \\
\hline Jurandir Maciel & PTB & $\mathrm{AD}$ & Pastor & 33.713 & Não Eleito \\
\hline Fernando Vilande & PSC & $\mathrm{AD}$ & Membro & 5.472 & Não Eleito \\
\hline Laura Loureiro & PSC & $\mathrm{AD}$ & Membro & 642 & Não Eleita \\
\hline Darci Domingues & PSC & $\mathrm{AD}$ & Membro & 375 & Não Eleita \\
\hline Fabio Negrine & PSC & Gideões Missionários & Missionário & 507 & Não Eleito \\
\hline Celso Moraes & PTB & Quadrangular & Pastor & 30.003 & Não Eleito \\
\hline Jaderson Maretoli & PTB & Missão Santa Maria & Pastor & 3.939 & Não Eleito \\
\hline Perci Pereira & PSL & $\begin{array}{c}\text { Igreja a Glória } \\
\text { de Deus }\end{array}$ & Pastor & 3.449 & Não Eleito \\
\hline Michele Bettega & PSC & Igreja de Cristo & Diácono & 441 & Não Eleita \\
\hline Rozélio Camargo & PSC & $\begin{array}{l}\text { Metodista } \\
\text { Wesleyana }\end{array}$ & Membro & 298 & Não Eleito \\
\hline Airton Borges & PSC & Cristo é a Solução & Pastor & 1.677 & Não Eleito \\
\hline Ezequiel Welter & PSC & $\begin{array}{c}\text { Cristo é a Solução } \\
\text { Renovada }\end{array}$ & Pastor & 371 & Não Eleito \\
\hline Marcos Calegari & PMDB & $\begin{array}{c}\text { Igreja Comunidade } \\
\text { Cristã }\end{array}$ & Pastor & 2.335 & Não Eleito \\
\hline $\begin{array}{l}\text { Paulo Roberto } \\
\text { da Silva }\end{array}$ & PMDB & Não identificada & Musico & 18.644 & Não Eleito \\
\hline
\end{tabular}

Debates do NER, Porto Alegre, ANo I6, N. 27, P. I45-I7I, JAN./Jun. 2015 


\begin{tabular}{c|c|c|c|c|l}
\hline Clovis da Silva & PTC & Não identificada & Pastor & 156 & Não Eleito \\
\hline Ana Neri Knupp & PSC & Não identificada & Membro & 1.112 & Não Eleita \\
\hline André Maia & PSC & Não identificada & Membro & 1.309 & Não Eleito \\
\hline Jair Martins & PSC & Não identificada & Cantor & 959 & Não Eleito \\
\hline Vagner Santos & PSC & Não identificada & Membro & 549 & Não Eleito \\
\hline Mario Gonçalves & PSC & Não identificada & Membro & 1.194 & Não Eleito \\
\hline Gilberto Santos & PSC & Não identificada & Membro & 722 & Não Eleito \\
\hline Tarcísio de Góis & PSC & Não identificada & Membro & 354 & Não Eleito \\
\hline Divaldino Luiz Pires & PSC & Não identificada & Membro & 1.714 & Não Eleito \\
\hline Eliane Campos & PSC & Não identificada & Membro & 1.620 & Não Eleita \\
\hline Adair Santos & PSC & Não identificada & Cantor & 732 & Não Eleito \\
\hline Elmar Cainelli & PSC & Não identificada & Membro & 838 & Não Eleito \\
\hline Total & & & & 516.257 & \\
\hline
\end{tabular}

Fonte: Organizado pelos autores.

Nota-se que o total de votos direcionados aos evangélicos para a Assembleia Legislativa é relativamente próximo àquele obtido pelos candidatos evangélicos à Câmara Federal, ou seja, 516.257 para a primeira e 589.417 para esta última.

\section{Afro-religiosos e espirita}

Como dissemos anteriormente, nas eleições de 2014 ao legislativo estadual do Rio Grande do Sul, compareceram dois candidatos que explicitaram publicamente o seu vínculo com o campo afro-religioso. São eles: Pai Antonio de Ogum, líder do Templo de Umbanda Pai Ogum Beira em Santa Cruz do Sul, que já concorreu a vereador pelo PT, nesta mesma cidade, em 2012. Obteve 454 votos. E Bara-Exu Olumide Betinho, que concorreu pelo PT e obteve 3.157 votos. Apresentou-se com uma proposta de identificação total com as religiões de matriz africana, começando por

Debates do NER, Porto Alegre, Ano I6, N. 27, P. I45-I7I, JAN./Jun. 2015 
utilizar seu nome religioso (Olumide) associado ao nome do orixá Bará, em uma posição polar de resistência e não identificação com a cultura cristã circundante. Com os dizeres "Quem é de Axé, quem é de Saravá vem com a gente", buscou congregar o apoio como representante das religiões de matriz africana. Alcançou 3.157 votos.

O candidato espírita, ou espiritualista, como ele também se chama, Marlon Santos, já tinha sido eleito deputado estadual na legislatura de 2002-2006. Antes disso, fora vereador em Cachoeira do Sul, onde alcançou fama como renomado curandeiro espírita. Nessa cidade, atendia, em todos os sábados, entre 800 e 1.200 pessoas que o procuravam em busca da cura. Nestas ocasiões, trabalhava em estado de transe ${ }^{19}$. Não se reapresentou como candidato nas eleições de 2006. Tentou retornar à Assembleia Legislativa em 2010, ficando na primeira suplência do PDT, com 33.174 votos. Nas eleições atuais de 2014, foi eleito com a maior votação do PDT: 91.100 votos.

\section{Católicos}

Pelo menos quatro candidatos ao parlamento estadual declararam sua pertença ao catolicismo durante a campanha eleitoral de 2014. Nenhum deles elegeu-se deputado. São eles: 2 fiéis, 1 pregador e 1 sacerdote. Este último é o padre capelão Wilson Pedro Lill, responsável pela Paróquia São Cristovão, em Passo Fundo, eleito vereador deste município em 2012. Concorreu pelo PSB e obteve 7.891 votos. O pregador é o engenheiro civil Luciano Martins, membro da Renovação Carismática Católica. Foi eleito vice-prefeito de Capão da Canoa em 2000 e concorreu em 2004 e 2012

${ }^{19}$ Em abril de 2003, disse-nos, em entrevista, o então parlamentar: "trabalho em estado de transe, que possibilita que a entidade espiritual (que já passou pela terra) atue por intermédio do mediador (ele próprio), auxiliando as pessoas que buscam o atendimento. No meu caso, entro em um transe completo, que inviabiliza minha consciência, pois, se eu ficar consciente, acabo atrapalhando o trabalho da entidade". E completou: "Entro em transe às oito horas da manhã, paro ao meio-dia, volto a uma hora da tarde e fico até quando tem gente para atender."

Debates do NER, Porto Alegre, Ano I6, N. 27, P. I45-I7I, JAN./Jun. 2015 
a vereador, ficando como suplente no último pleito. Nas eleições de 2014, concorreu pelo PMDB e obteve 13.878 votos. Os dois outros fiéis católicos são: Aldacir Oliboni, do PT, político bastante conhecido no meio católico, principalmente por sua atuação como Cristo, desde 1981, durante as representações da Paixão de Cristo em Porto Alegre (Bem; Tadvald, 2004), eleito três vezes vereador, em 2000, 2004 e 2008, e suplente para a Assembleia Legislativa em 2010, assumindo em 2012. Obteve 19.162 votos. E Edson da Rosa, eleito três vezes como vereador em Caxias do Sul, em 2004, 2008 e 2012, tendo sido secretário municipal de educação entre 2009 e 2011. Concorreu pelo PMDB e recebeu 14.858 votos.

\section{RELIGIÔES E ELEIÇŌES: REINCIDÊNCIAS E ESPECIFICIDADES}

Uma breve comparação com o ocorrido nas eleições de 2010 mostra que, relativamente à disputa ao Palácio Piratini ${ }^{20}$, tanto naquela quanto na eleição de 2014, os seus candidatos têm buscado apoios junto a líderes e organizações religiosas. Assim, o candidato Tarso Genro, vencedor das eleições em 2010, reuniu-se naquela campanha com pastores da Igreja Assembleia de Deus e da Igreja Mundial. Outro candidato, José Fogaça, participou de cerimônia de inauguraçáo do templo da igreja Bola de Neve, no bairro Sarandi, em Porto Alegre, enquanto que a então governadora Yeda Crusius, compareceu num encontro da Universal no Gigantinho e conquistou o apoio de representantes do Partido Republicano Brasileiro (PRB). Yeda Crusius ainda compareceu, em Porto Alegre, à cerimônia do ano novo judaico, na Sociedade Israelita Brasileira de Cultura e Beneficência.

As aproximações dos candidatos ao executivo com lideranças religiosas, sobretudo evangélicas, é, portanto, recorrente, e isso em praticamente todas as eleições que se sucederam ao período ditatorial no país. Como vimos, isso também ocorreu nas eleições que acabam de se realizar. Por isso mesmo, como dissemos em outro lugar (Oro; Mariano, 2010, p. 13), toda essa

${ }^{20}$ Sede do governo estadual no Rio Grande do Sul.

Debates do NER, Porto Alegre, Ano I6, N. 27, P. I45-I7I, JAN./Jun. 2015 
reincidência indica "[...] que os candidatos a cargos eletivos não desconsideram na campanha eleitoral o potencial político detido pelas organizações religiosas, sobretudo as evangélicas. Como outros autores já mostraram, esta situação é recorrente em todo o Brasil (Burity, 1997; Sanchis, 1991; Mariano; Hoff; Dantas, 2006)".

Relativamente à disputa por cadeiras na Câmara Federal, recordamos que, nas eleições de 2010 no Rio Grande do Sul, compareceram seis candidatos religiosos, todos evangélicos, dos quais somente um deles, Onyx Lorenzoni, logrou ser eleito. Além dele, concorreram dois pastores pentecostais (Ronaldo Nogueira, da Assembleia de Deus, e Valdir Canal, da Igreja Universal), o cantor gospel Gauchinho de Deus (associado à Igreja Internacional da Graça de Deus) e dois pastores de igrejas evangélicas históricas (Getulio Vargas, da Batista Betel, e Elias Vidal, da Adventista do Sétimo Dia). Nas eleições atuais, a maioria deles compareceu novamente como candidato, menos Elias Vidal. Desta feita, Onyx Lorenzoni e Ronaldo Nogueira foram eleitos, Valdir Canal apresentou-se como suplente ao senado na candidatura de Simone Leite e Getulio Vargas concorreu novamente a deputado federal, obtendo uma votação bem aquém daquela alcançada em 2010. Naquela eleição, concorrendo pelo PSC, obteve 17.057 votos enquanto que nas eleições de 2014, desta feita concorrendo pelo PSL, obteve 2.237 votos.

Portanto, diferentemente do que ocorreu nas eleições precedentes, quando somente um candidato evangélico conquistou uma cadeira na Câmara Federal, nas eleiçôes atuais, quatro candidatos evangélicos foram eleitos para a Câmara Federal pelo Rio Grande do Sul: Onyx Lorenzoni (Igreja Luterana), Ronaldo Nogueira (Assembleia de Deus), João Derly (Igreja Presbiteriana) e Carlos Gomes (Igreja Universal).

No que concerne à disputa para a Assembleia Legislativa do Estado do Rio Grande do Sul, em 2010, foi eleito somente um pastor evangélico. Ocorreu, então, a reeleição do pastor Carlos Gomes, da Universal, que, nas eleições atuais, foi eleito como deputado federal. Ainda nas eleições de 2010, outras denominações evangélicas, como a Assembleia de Deus e a Quadrangular, apresentaram candidatos provenientes de suas fileiras, mas 
nenhum deles foi eleito. Da Assembleia de Deus, compareceram, no mínimo, cinco pastores e uma fiel que se declararam candidatos e membros dessa denominação. Alguns foram apoiados oficialmente pela cúpula dirigente da Igreja enquanto que outros se lançaram como candidatos por conta própria. O resultado foi, como já havia ocorrido em eleições anteriores, a pulverização dos votos e a não eleição de nenhum dos candidatos, por excesso de opções dentro de uma mesma denominação. Já a Igreja Quadrangular havia apresentado um candidato, que também não logrou ser eleito. $\mathrm{O}$ mesmo ocorreu com o representante da Igreja Mundial do Poder de Deus.

Nas eleições de 2014, o sucesso evangélico foi maior: elegeram-se três deputados ao parlamento estadual. Contribuiu, para tanto, o fato de que as três denominaçôes que emplacaram seus representantes adotaram o modelo da candidatura oficial, inaugurada com a Igreja Universal há algumas décadas (Oro, 2003). Ou seja, essas denominações procederam à escolha de candidatos membros das mesmas, escolhas essas realizadas não pelas bases, mas pelas cúpulas dirigentes, e concentraram neles toda a sua capacidade de mobilização visando às suas eleições, o que, via de regra, tem resultados positivos, que podem ser contrapostos a estas iniciativas isoladas de religiosos sem o apoio massivo dos líderes de suas denominações, tendo como consequência uma votação baixa ou, no caso de vários candidatos, na pulverização dos votos.

Há, porém, diferenças de prática de campanha eleitoral entre as denominaçóes que adotaram o modelo da candidatura oficial. A Universal e a Mundial apresentaram seus candidatos durante os cultos - sobretudo os dominicais - e, ao término dos mesmos, incentivavam os irmãos a votarem neles. Ou seja, naquelas duas denominações, a propaganda eleitoral ocorreu também no interior dos templos. Já na Internacional da Graça, a campanha ocorreu "da porta para fora". Isto é, foi interditado pela cúpula dirigente de se falar em eleições no interior do recinto religioso. Foi também proibido apresentar a candidata oficial ou distribuir material de campanha dos candidatos oficiais da própria Igreja. Tudo isso ocorreu da porta do templo para fora. É neste local que foi entregue o material de campanha aos membros da 
igreja e demais transeuntes ${ }^{21}$. Neste particular, a própria candidata Liziane Bayer assim se expressou:

A igreja tem aquela restrição. A gente não pode falar de política dentro da igreja. Tu trabalha uma conscientização das pessoas, a necessidade de tu te envolver, de tu não se excluir de política, mas ao mesmo tempo, tu não pode pedir voto lá dentro. ${ }^{22}$

A candidata ainda salientou que o fato de ser filha de uma importante liderança da igreja e ter realizado trabalho como apresentadora de televisão ajudaram na divulgação de sua candidatura.

Esta peculiar divisão entre política e religião é comum dentro do segmento evangélico e já foi trabalhado anteriormente (Pedde, 2004; Meirelles; Weege; Picolloto, 2006). Porém, isso não impede o desenvolvimento neste meio religioso da necessidade da intervenção da religião na manutenção dos princípios cristãos dentro da administração pública, seja pela eleição de religiosos ou pelo apoio de candidatos que defendem tais princípios. A partir daí, surge uma variedade de posiçôes: o afastamento do político mas defendendo o voto consciente (Congregação Cristã e Deus É Amor),

${ }^{21}$ No material de campanha dos seus candidatos no Rio Grande do Sul (Missionário Volnei e Cajar Nardes), o Missionário R. R. Soares, da Igreja Internacional da Graça, convocou os seus fiéis a votarem nestes dizendo que "[...] é no parlamento que as leis que nos regem são feitas [...]. Para não termos nenhum impedimento na realização da obra do Senhor, faz-se necessário eleger homens de caráter, compromissados com a verdade e a moralidade [...]. Os favoráveis ao aborto não desistem de lutar para que muitos bebês não nasçam." E finaliza dizendo que "Se as pessoas de bem se calarem, as famílias serão destruídas em breve." O tema da valorização da família, bem como o combate à drogadição, também figurou no material de campanha dos candidatos oficiais da Universal. Por exemplo, um dos compromissos do candidato a deputado estadual Sergio Peres era a "valorização da família para combater a drogadição e a criminalidade", além de "estruturação dos centros de tratamento de dependentes químicos".

22 Entrevista ao Programa Assembleia Entrevista. Disponível em: < https://www.youtube. com/watch?v=pCB9aaZVIZQ>. Acesso em: 12 jan. 2015.

Debates do NER, Porto Alegre, Ano i6, N. 27, P. I45-I7I, JAN./Jun. 2015 
o não lançamento de candidatos mas o apoio a um candidato específico, religioso ou não, bastante comum em denominações independentes, ou o lançamento de candidatos oficiais (IURD, IIGD e IMPD). São também demarcados limites específicos entre o sagrado e o profano nas opções de cada denominação ao se inserir na política, decorrendo daí a importância de criar um distanciamento perceptível para os fiéis, um dentro e um fora, um espaço religioso e um espaço secular, ou o reconhecimento de um religioso, mesmo que este mantenha uma imagem secular.

A diferença entre as denominações também apareceu no material impresso. $\mathrm{Na}$ Internacional da Graça, as candidatas (a deputado estadual e federal) aparecem acompanhadas da imagem de R. R. Soares, fundador e líder geral da denominação. $\mathrm{O}$ mesmo ocorreu no material da Mundial, onde, além da figura do candidato, ao fundo do santinho aparece o candidato sendo abençoado pelo Apóstolo Valdemiro Santiago, figurando abaixo a seguinte frase atribuída a ele: "Esse é o meu candidato, da minha família, dos meus amigos". Já com os candidatos da Universal, não há uma associação com a imagem do líder máximo da denominação, Edir Macedo, mas com os líderes locais, como o Pastor Carlos Cucato, responsável pela Universal no Rio Grande do Sul, além de não haver uma referência direta ao pertencimento do candidato à Universal (como o título de pastor junto ao nome).

Quanto à Assembleia de Deus, mais uma vez, nenhum dos seus candidatos logrou se eleger, insucesso que se repete desde 2006, principalmente pela pulverização dos votos entre os vários candidatos da denominação. Embora a Assembleia também tenha adotado o modelo do encaminhamento da candidatura oficial, não logrou eleger o seu representante Jurandir Maciel, uma vez que essa denominação não concentrou, como fizeram as igrejas anteriormente referidas, a campanha neste candidato, deixando os irmãos livres para votarem em quem quiserem.

Entre os afro-religiosos, tivemos uma redução significativa. Em 2010, apesar de nenhum candidato eleger-se, os três candidatos em questão, a saber: Pedro de Oxum, Tony e Vera Soares, juntos, somaram 17.076 votos. Já em 2014, os dois candidatos que se apresentaram chegaram somente a 3.611 votos.

Debates do NER, Porto Alegre, Ano I6, N. 27, P. I45-I7I, JAN./Jun. 2015 


\section{CONSIDERAÇÕES FINAIS}

Como indicam outros números da revista Debates do NER consagrados ao tema da relação entre religião e eleições ${ }^{23}$, o mútuo aparelhamento por parte dos segmentos religiosos e das organizações partidárias buscando o sucesso eleitoral também pôde ser notado tanto em espaços propriamente religiosos como em atividades de caráter público por ocasião da disputa eleitoral de 2014. Aliás, o presente texto mostrou que no Rio Grande do Sul ocorreu um aumento em 2014 em relação a 2010 de candidatos eleitos que se auto-definiram como religiosos, mais especificamente, evangélicos. Isto significa que doravante teremos no legislativo estadual uma pequena, mas sempre não desprezível, bancada evangélica, à semelhança do que ocorre no congresso nacional. Aqui, recordamos que o número de membros das bancadas evangélicas tem oscilado segundo as legislaturas. Ela foi de 65 membros em 2002, 42 em 2006, 63 em 2010 (Campos, 2010). Atualmente, os dados disponíveis mostram que a referida bancada evangélica é formada por 74 membros. ${ }^{24}$ Embora se saiba que a bancada não constitua um grupo homogêneo, ela tem se mostrado uma força política nada desprezível, sobretudo quando entram em pauta determinados temas de ordem valorativa e moral como o aborto, união civil de homossexuais, pesquisas com células tronco e outros.

Isso significa que se observa na sucessão dos pleitos eleitorais uma tendência recorrente de fortalecimento da ideia segundo a qual, em nosso país, religião e política são instâncias sociais que se influenciam mutuamente

${ }^{23}$ DEBATES DO NER. Porto Alegre: UFRGS, v. 1, n. 3, 2001.

DEBATES DO NER. Porto Alegre: UFRGS, v. 2, n. 6, 2004.

DEBATES DO NER. Porto Alegre: UFRGS, v. 2, n. 10, 2006.

DEBATES DO NER. Porto Alegre: UFRGS, v. 2, n. 18, 2012.

DEBATES DO NER. Porto Alegre: UFRGS, v. 1, n. 23, 2013.

${ }^{24}$ Disponível em: <http://www.diap.org.br/index.php?option=com_content\&view=article \&id=24534:bancada-evangelica-levantamento-preliminar-do-diap-identifica43-deputados\&catid=59:noticias\&Itemid=392>. Acesso em: 12 jan. 2015.

Debates do NER, Porto Alegre, Ano i6, N. 27, P. I45-I7I, JAN./Jun. 2015 
num constante movimento de implicações e reordenações recíprocas (Burity, 2000). Esta é uma realidade que não pode ser desconsiderada teoricamente ou obscurecida ideologicamente. A sua não percepção seria prova de incompreensão do que ocorre na sociedade. Ou, como registrou Otavio Velho, de forma direta e certeira: "Quem acha que religião e política não se misturam, não entende nada nem de religião, nem de política" (Velho, 2012, contracapa apud Oro et al., 2012).

\section{REFERÊNCIAS}

BEM, Daniel F. De; TADVALD, Marcelo. A apropriação da discursividade religiosa pelo campo político. Debates do NER, Porto Alegre, ano 5, n. 6, p. 63-82, dez. 2004.

BURITY, Joanildo; MACHADO, Maria das Dores (Org.). Os votos de Deus Evangélicos, política e eleições no Brasil. Recife: Fundação Joaquim Nabuco, Ed. Massangana, 2006.

BURITY, Joanildo. Identidade e Politica no campo religioso. Recife: IPESPE; Ed. Universitária/UFPE, 1997.

- Religião e política na fronteira: desinstitucionalização e deslocamento numa relação historicamente polêmica. In: CONGRESSO LATINO-AMERICANO DE RELIGIÃO E ETNICIDADE, 8., 27 jun./5 jul. 2000, Pádua, Itália. Associação Latino-americana para o Estudo das Religiōes, 2000. Mimeografado. CAMPOS, Leonildo Silveira. O complicado "Governo dos justos": avanços e retrocessos no número de deputados federais evangélicos eleitos em 2006 e 2010. Debates do NER, Porto Alegre, n. 18, jul./dez. 2010, p. 39-82.

HERVIEU-LEGER, Danièle. Croire en modernité: au-delà de la problématique des champs religieux et politiques. In: MICHEL, Patrick. Religion et Démocratie. Paris: Albin Michel, 1997. p. 361-382.

Debates do NER, Porto Alegre, ANo I6, N. 27, P. I45-I7I, JAn./Jun. 20 I5 
MARIANO Ricardo; HOFF Marcio; DANTAS, Toty Ypiranga. Evangélicos sanguessugas, presidenciáveis e candidatos gaúchos: a disputa pelo voto dos grupos religiosos. Debates do NER, Porto Alegre, v. 10, n. 7, p. 65-78, jul./dez. 2006.

MEIRELLES, Mauro; WEEGE, Adriana; PICOLLOTO, Mariana. Vivendo entre dois mundos: os evangélicos e a política dentro e fora dos templos frente às eleições de 2010. Debates do NER, Porto Alegre, n. 18, p. 111-127, 2010.

MICHEL, Patrick. Religion et Démocratie. Paris: Albin Michel, 1997.

MOREIRA, A. S.; MARIANO, Ricardo. La crescita del Pentecostalismo in Brasile. Religioni e Società, Roma, n. 73, p. 32-45, 2012.

NOVAES, Regina. A divina política: Notas sobre as relações delicadas entre religião e política. Revista USP, São Paulo, n. 40, p. 60-81, mar./maio 2001.

ORO, Ari Pedro; MARIANO, Ricardo. Eleições 2010: religião e política no Rio Grande do Sul e no Brasil. Debates do NER, v. 18, p. 11-38, 2010.

ORO, Ari Pedro. Ascension et déclin du pentecôtisme politique au Brésil. Archives de Sciences Sociales des religions, Paris, n. 149, p. 151-168, 2010.

. "Religious Politicians" and "Secular Politicians" in Southern Brazil. Social Compass, v. 54, n. 4, p. 583-592, 2007.

Organização eclesial e eficácia política: o caso da Igreja Universal do Reino de Deus. Civitas, Porto Alegre, PUC/RS, v. 3, n. 1, p. 97-110, jun. 2003.

ORO, Ari Pedro; JUNIOR, Erico Tavares de Carvalho. Religiōes e eleições 2012 em Porto Alegre. Debates do NER, Porto Alegre, ano 14, n. 23, p. 109-144, jan./jun. 2013.

PEDDE, Valdir. A percepção dos fiéis pentecostais quanto ao envolvimento de suas denominações na atividade política. Debates do NER, Porto Alegre, n. 6, 2004. 
RIBEIRO, Renato Janine. Religião e política no Brasil contemporâneo. In: FRIDMAN, Luis Carlos (Org.). Política e Cultura: Século XXI. Rio de Janeiro: ALERJ; Relume Dumará, 2002. p. 99-110.

SANCHIS, Pierre. Desencanto e formas contemporâneas do religioso. Ciencias Sociales y Religión, Porto Alegre, Ano 3, n. 3, p. 27-43, 2001.

VELHO, Otavio. Contracapa. In: ORO, Ari Pedro; STEIL, Carlos Alberto; CIPRIANI, Roberto; GIUMBELLI, Emerson. A religião no espaço público: atores e objetos. São Paulo: Terceiro Nome, 2012.

Recebido em: 20/01/2015

Aprovado em: 03/03/2015 